\title{
Efficacy of an Extract of Ocimum tenuiflorum (OciBest) in the Management of General Stress: A Double-Blind, Placebo-Controlled Study
}

\author{
Ram Chandra Saxena, ${ }^{1}$ Rakesh Singh, ${ }^{2}$ Parveen Kumar, ${ }^{3}$ \\ Mahendra P. Singh Negi, ${ }^{4}$ Vinod S. Saxena, ${ }^{5}$ Periasamy Geetharani, ${ }^{6}$ \\ Joseph Joshua Allan, ${ }^{6}$ and Kudiganti Venkateshwarlu ${ }^{6}$ \\ ${ }^{1}$ Clinical Pharmacology, OP Chaudhry Hospital and Research Centre, Lucknow 226 015, India \\ ${ }^{2}$ General Medicine and Cardiology, Lucknow 226 001, India \\ ${ }^{3}$ General Medicine, Bhatnagar Nursing Home, Lucknow 226012 , India \\ ${ }^{4}$ Statistics Centre, Institute for Data Computing and Training, Lucknow 226 012, India \\ ${ }^{5}$ Sannidhi, Gurgaon, India \\ ${ }^{6}$ Research and Development Centre, Natural Remedies, Karnataka, Bangalore 560 100, India
}

Correspondence should be addressed to Joseph Joshua Allan, joshua@naturalremedy.com

Received 20 April 2011; Accepted 12 July 2011

Academic Editor: José Luis Ríos

Copyright (C) 2012 Ram Chandra Saxena et al. This is an open access article distributed under the Creative Commons Attribution License, which permits unrestricted use, distribution, and reproduction in any medium, provided the original work is properly cited.

\begin{abstract}
A randomized, double-blind, placebo-controlled study was conducted to evaluate the efficacy of OciBest, an extract of Ocimum tenuiflorum Linn. in symptomatic control of general stress. The participants received either placebo $(n=79)$ or OciBest $(n=71$; $1200 \mathrm{mg}$ of actives per day) for six weeks. The severity of stress-related symptoms was self-evaluated by patients at weeks $0,2,4$ and 6 of the trial period using a symptom rating scale. After six weeks of intervention, scores of symptoms such as forgetfulness, sexual problems of recent origin, frequent feeling of exhaustion, and frequent sleep problems of recent origin decreased significantly $(P \leq 0.05)$ in OciBest group as compared with placebo group. Also, the total symptom scores of OciBest group revealed significant reduction $(P \leq 0.05)$ as compared to placebo group. The overall improvement in OciBest group was found to be 1.6 times or $39 \%$ more in the control of general stress symptoms with respect to placebo. No adverse events were reported during the study. The findings revealed that OciBest was found to be effective and well tolerated by all the patients over the six weeks of study period.
\end{abstract}

\section{Introduction}

In modern society, stress is a common problem faced by everyone in day-to-day life from different sources like job, family problems, pollution, noise etc. Stress is defined as psychological, physiological, and behavioural response by individuals when they perceive a lack of equilibrium between the demands placed upon them and their ability to meet those demands [1]. The level of stress depends on the threshold of each individual. Over a period of time the response to stress aggravates and leads to ill-health $[1,2]$.

The common symptoms of stress include fatigue, tenseness, irritability, apathy, sleeping disorders, emotional instability, thoughts, and concentration problems [3]. Present generation people are more ravaged by the consequences of stress than at any time in past, and financial expenses in terms of long-term sick leave due to stress-related mental disorders are extensive [4]. Nearly $75 \%$ to $90 \%$ patient visits to primary care physicians are related to stress problems. In USA, health and efficiency costs of worker stress were reported to be between $\$ 50$ and $\$ 150$ billion per annum, and irrepressible stress revealed to be high risk factor for cancer and heart disease than either cigarette smoking or intake of high-cholesterol diets [5-8]. Psychological problems due to enormous workloads among employees have increased at a faster rate in many countries. In England, around 40 million workdays per year have been lost owing to mental and emotional problems [9]. 
Management of any unusual stress has acquired significant implications in daily life. Whereas complete avoidance of stress is unlikely, any intervention that facilitates elevation of threshold level can be beneficial. In order to curtail the economic losses towards the stress-related disorders and to improve the quality of life, traditional therapies seem to be promising alternatives. Indian system of traditional medicine describes remedies based on herbal supplementation, minerals, and other therapeutic procedures for enhancing physical and mental performance to evade the stress levels [10-13].

Ocimum tenuiflorum Linn. (synonym: Ocimum sanctum), generally known as Tulsi or Holy Basil, belongs to family lamiaceae. In Ayurveda, O. tenuiflorum has been used for adaptogenic/antistress activity [14]. It has been widely reported to possess antipyretic [15], antiasthmatic [16], antioxidant $[17,18]$, analgesic [19], and anti-inflammatory properties [20]. O. sanctum prevented reduction in the levels of brain catecholamine and monoamine oxidase and increase in dopamine and 5-hydroxytryptamine in rats exposed to swimming and gravitational stress [21].

Despite the availability of extensive preclinical evidences on antistress activity of $O$. tenuiflorum, authenticated clinical data are found to be lacking. A study by Bhattacharyya et al. that revealed the promising effects of $O$. sanctum ( $500 \mathrm{mg} / \mathrm{capsule}$, twice daily after meal) for a period of two months in the management of patients suffering from generalized anxiety disorder (GAD) remains the only pertinent clinical evidence published on the medicinal herb till date [22].

\section{Participants and Methods}

2.1. Participants. The present study was carried out at two different centers in Lucknow, India between April 2008 and September 2009. Patients were recruited according to the inclusion criteria if they (i) were aged between 1865 years, (ii) had given written consent, (iii) agreed to come for followup at week 2, 4, and 6 irrespective of any relief or appearance of side effects, and (iv) were suffering from at least any three of the symptoms of stress shown (Table 1). Patients were excluded if they (i) were unable to give voluntary consent, (ii) had history of significant cardiac, hepatic, renal, brain, or blood-allergic diseases, (iii) had physical disabilities, (iv) were taking allopathic or herbal medicines or participating in any other clinical trial, or (v) were pregnant/breast feeding.

One sixty-seven patients were screened for selection criteria, of which 158 were selected for the study after obtaining the written consent from each individual by the investigators. The study was approved by Institutional Ethics Committee.

2.2. Study Intervention. OciBest, an extract of whole plant of O. tenuiflorum Linn. was developed by M/s Natural Remedies Pvt. Ltd., Bangalore, India. The extract was ensured to comply with phytochemical specifications, namely, Ociglycoside-I (Hydroxychavicol glucoside/4-allyl-1-O- $\beta$-Dglucopyronosyl-2-hydroxybenzene; $>0.1 \% \mathrm{w} / \mathrm{w}$ ), rosmarinic
TABLE 1: Symptoms of stress.

(i) Headache

(ii) Palpitation at rest

(iii) Abnormal perception of hearing

(iv) Blurring of vision

(v) Forgetfulness

(vi) Sexual problems of recent origin

(vii) Frequent GI symptoms, lack of appetite, or dislike of even favourite food

(viii) Abnormal movements of upper limb, tics, tremors, scratching

(ix) Abnormal sensory perceptions particularly of lower limbs and face

(x) Quarrelsome behaviour with later realizing of mistake

(xi) Frequent feeling of exhaustion or overworked

(xii) Frequent sleep problems of recent origin

(xiii) Avoidance of even familiar people

(xiv) Missing appointments for other things less important

acid $(>0.2 \% \mathrm{w} / \mathrm{w})$, and triterpene acids $(>2.5 \% \mathrm{w} / \mathrm{w})$. The composition adhered to the international quality requirements which included analysis of solvent residues, heavy metals, pesticide residues, and microbial contamination. The placebo capsules contained microcrystalline cellulose. Each OciBest capsule contained $400 \mathrm{mg}$ of actives. The placebo and OciBest were filled in " 0 " size blue-coloured, hardgelatin capsules that could not be distinguished from each other. Each container was packed with 42 capsules and labeled with code number.

2.3. Randomization and Blinding. The patients enrolled for clinical trial were allotted to placebo and OciBest groups. To identify the patient code, a list of unique integer random numbers were obtained after generating the random allocation number using a computer-aided random series programme. According to the random allocation sequence, the distinct random numbers were mentioned in the respective containers (placebo or OciBest). The packed containers were dispatched from Natural Remedies Pvt. Ltd., Bangalore, India to the study centers. The entire process was accomplished in concealed manner. As per enrollment and random allocation sequence the pharmacist dispensed the study intervention and was responsible for the same. The study investigators, pharmacist, and the participants were all blinded during the trial period.

2.4. Study Protocol. The study was performed in a randomized, double-blind, placebo-controlled manner. One fiftyeight patients were selected for the study and randomly assigned to placebo and OciBest group. Each patient was handed over one container and advised to take one capsule after breakfast and two capsules after dinner (total $1200 \mathrm{mg}$ of actives per day) for 2 weeks. After 2 weeks, the patient was asked to report for followup and symptoms reassessment. Any unconsumed capsules were counted and recorded for 
compliance. Fresh container of 42 capsules was provided after recording the compliance. Similar process was repeated when the patient reported for followup during week 4 .

2.5. Outcome Measures. The symptom scores of patients (Table 1) were assessed on week 0 and thereafter followup on weeks 2, 4, and 6 of the study period. On each occasion, the patients were asked to grade themselves for all individual symptoms based on the symptom rating scale [23].

2.6. Sample Size. The required sample size for difference between two means, that is, for a two sample $t$-test was estimated according to Dell et al. [24]. The sample size was calculated with a power of $90 \%$ and value of alpha $=0.05$. Thus, minimum 65 subjects were required for each group and total 130 subjects for the whole study. Due to selflimiting condition in stress and as drop outs are common in clinical trial [25], additional subjects were added in each group.

2.7. Statistical Analysis. One hundred and fifty participants were considered for statistical analysis. The baseline demographic characteristics of two groups were compared by independent Student's $t$-test. The score of each symptom was analyzed using RMANOVA. The statistical significance was set at $P \leq 0.05$. The statistical applications were performed using SPSS (version 13) and STATISTICA (version 7.0) softwares. The effect of two groups on each symptom and total symptoms scores were calculated as the reduction in symptom severity scores from baseline (week 0) to final assessment (week 6). The effect size of individual and total symptoms was calculated as the difference between the effects of placebo and OciBest. The overall effect size (\%) between two groups was calculated as

$$
\text { Overall effect size }(\%)=\left[\frac{\text { Ocibest }- \text { Placebo }}{\text { Ocibest }}\right] \times 100 \text {. }
$$

\section{Results}

3.1. Demographic Data. Out of 167 subjects assessed for eligibility, a total of 158 patients (placebo $=82 ; 45$ males and 37 females and OciBest $=76$; 44 males and 32 females) who fulfilled the selection criteria and willing to give informed consent were enrolled in the study and randomized to either placebo or OciBest groups. On comparison, the demographic characteristics of all patients at baseline did not differ significantly in any of the parameters (Table 2).

3.2. Symptomatic Assessment of Efficacy. The symptom scores of patients of placebo and OciBest groups were summarized in Table 3. There was no significant difference between the individual symptom scores of participants of OciBest group as compared to placebo group on week 0 . In both the groups, mean scores of all individual symptoms showed a decreasing trend from week 0 to week 6 except for few symptoms in placebo which either remained constant (Avoidance of even
TABLE 2: Summary of demographic information.

\begin{tabular}{lccc}
\hline Characteristics & Placebo & OciBest & $t$-value \\
\hline Male/female & $45 / 37$ & $44 / 32$ & - \\
Age (years) & $47.56 \pm 1.11$ & $48.53 \pm 1.16$ & $0.60^{\mathrm{ns}}$ \\
Weight $(\mathrm{kg})$ & $64.77 \pm 1.19$ & $64.30 \pm 1.16$ & $0.28^{\mathrm{ns}}$ \\
Height $(\mathrm{cm})$ & $161.07 \pm 0.92$ & $163.13 \pm 1.20$ & $1.37^{\mathrm{ns}}$ \\
Heart rate/min & $79.20 \pm 0.77$ & $81.58 \pm 1.11$ & $1.79^{\mathrm{ns}}$ \\
BP diastolic $(\mathrm{mmHg})$ & $134.88 \pm 1.87$ & $133.28 \pm 1.85$ & $0.61^{\mathrm{ns}}$ \\
BP systolic $(\mathrm{mmHg})$ & $83.99 \pm 0.85$ & $82.58 \pm 0.87$ & $1.16^{\mathrm{ns}}$ \\
\hline
\end{tabular}

Values are expressed as mean \pm SEM; Placebo $n=82$; OciBest $n=76$ Ns-non significant.

familiar people, and missing appointments) or got aggravated (Blurring of vision, abnormal sensory perceptions, and frequent sleep problems) from week 4 to week 6 .

Mean scores of all symptoms in OciBest group decreased significantly $(P \leq 0.05)$ from week 0 to weeks 2,4 , and 6 except for sexual problems of recent origin at week 2 while placebo group showed either nonsignificant decrease (abnormal perception of hearing, sexual problems of recent origin, abnormal sensory perceptions, avoidance of even familiar people, and missing appointments) or significant decrease from week 0 to weeks 2, 4, and 6 in few symptoms (headache, palpitation at rest, frequent gastrointestinal (GI) symptoms, frequent feeling of exhaustion, and frequent sleep problems) and week 0 to weeks 4 and 6 in other symptoms (Blurring of vision, forgetfulness, and quarrelsome behaviour). Significant decrease was noticed in abnormal movements only from week 0 to week 6 in placebo-treated group.

Among all parameters, mean scores of headache, palpitation at rest, frequent GI symptoms, and frequent sleep problems decreased significantly $(P \leq 0.05)$ from week 2 to weeks 4 and 6 , and mean scores of forgetfulness, sexual problems of recent origin, quarrelsome behaviour and frequent feeling of exhaustion decreased significantly $(P \leq 0.05)$ from week 2 to week 6 in OciBest group. But in placebo group, most of the symptoms showed nonsignificant decrease except in few symptoms significant decrease $(P \leq$ 0.05 ) was noticed from week 2 to weeks 4 and 6 (frequent GI symptoms, frequent feeling of exhaustion and frequent sleep problems) and week 2 to week 6 (headache and quarrelsome behaviour).

On comparison, mean scores of forgetfulness, sexual problems of recent origin, quarrelsome behaviour, frequent feeling of exhaustion and frequent sleep problems decreased significantly $(P \leq 0.05)$ from week 4 to week 6 in OciBest group while in placebo group, all symptoms showed nonsignificant decrease from week 4 to week 6 except for quarrelsome behaviour.

Comparing mean between both groups, the effect of both the treatments on all symptoms at week 2 and 4 was found to be the same while at week 6 , symptoms of forgetfulness, sexual problems of recent origin, frequent feeling of exhaustion, and frequent sleep problems improved significantly $(P \leq 0.05)$ in OciBest-treated group as compared to placebo group. 


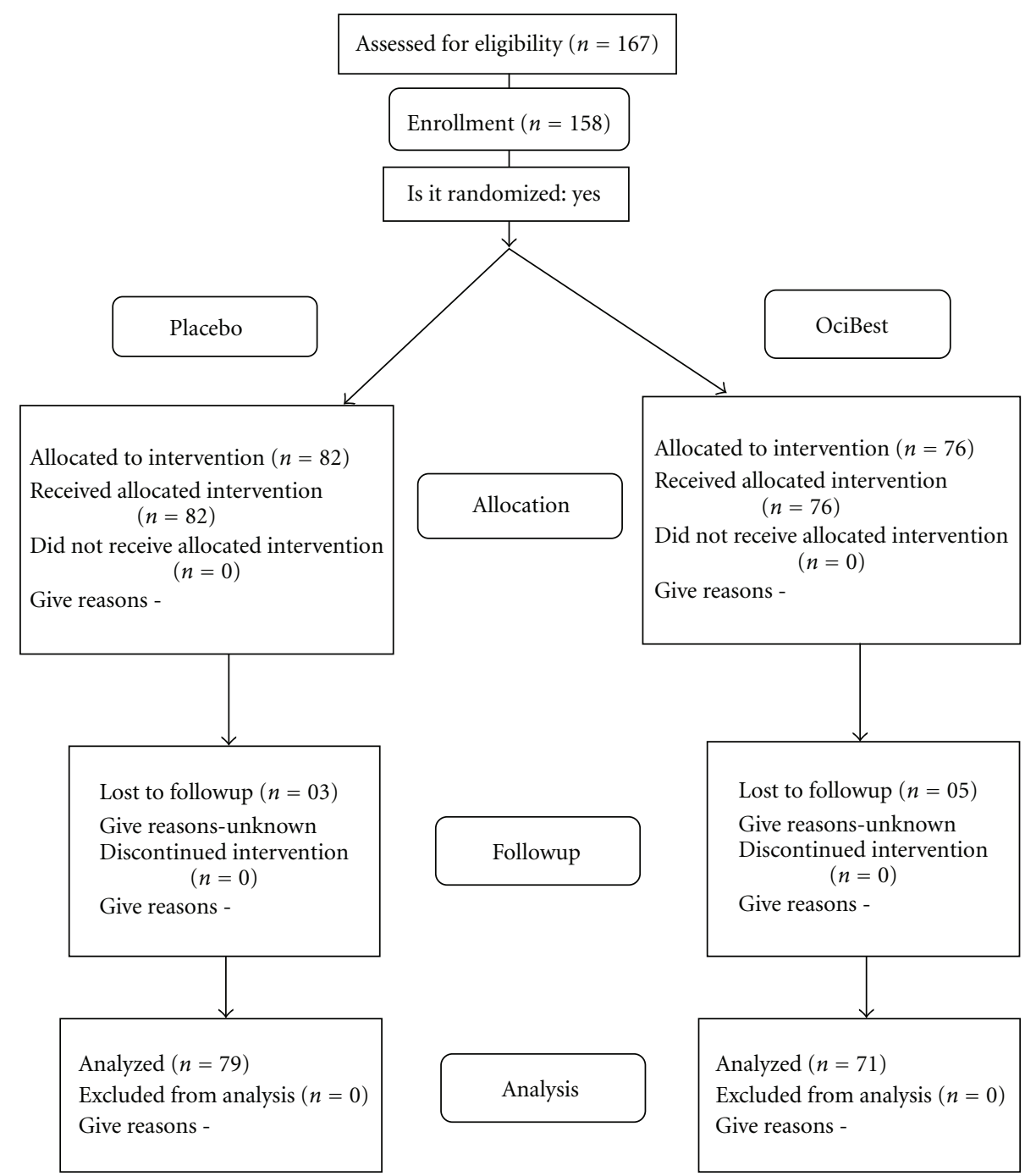

Figure 1: Disposition of patients.

Total scores of all symptoms in both the groups decreased significantly $(P \leq 0.05)$ at all consecutive week intervals as compared to weeks 0,2 and 4 . At the end of the study, the between groups analysis of total symptom scores of OciBest revealed significant reduction $(P \leq 0.05)$ as compared to placebo. The effect of OciBest over placebo on comparison was considerable for all stress parameters. The overall effect size of OciBest was found to be 39\% (1.6 times) higher than placebo (Table 3).

3.3. Drop Outs. Out of 158 enrolled patients at baseline, three patients in placebo and five patients in OciBest treated group did not turn up for followup and were excluded from data analysis. Thus symptom scores of 79 patients in placebo and 71 in test group were analyzed statistically (Figure 1).

3.4. Adverse Effects. None of the patients from both groups (placebo and OciBest) reported any adverse effects.

\section{Discussion}

Current pharmacological investigations focus on alleviating symptoms of stress since physical strains and psychological pressures have become integral and inevitable components of present life situations. Recently, herbal extracts and supplements have gained global recognition for stress-relieving potentials [26-28], in addition to popular medicinal uses and widely accepted safety profile [29-32].

The findings of a recent study proposed that people suffering from uncontrolled stress experienced impairment of short-term memory and other relevant functions in the prefrontal cortex induced by protein kinase $C$ [33]. In the current study, supplementation with OciBest significantly decreased the intensity of forgetfulness to about one-third observed in placebo group. Additionally, the effect size was found to be the maximum (0.70) which elucidated that the participants of OciBest group were highly improved from forgetfulness than from any other symptoms. 
TABLE 3: Effect of OciBest on symptom scores of stress.

\begin{tabular}{|c|c|c|c|c|c|c|c|}
\hline \multirow{2}{*}{ Symptoms } & \multirow{2}{*}{ Groups } & \multicolumn{4}{|c|}{ Assessment period } & \multirow{2}{*}{ Effect $^{X}$} & \multirow{2}{*}{ Effect size ${ }^{\mathrm{Y}}$} \\
\hline & & Week 0 & Week 2 & Week 4 & Week 6 & & \\
\hline \multirow{2}{*}{ Headache } & Placebo & $1.34 \pm 0.17$ & $0.96 \pm 0.14^{\mathrm{a}}$ & $0.78 \pm 0.13^{\mathrm{a}}$ & $0.58 \pm 0.12^{\mathrm{ab}}$ & $0.76 \pm 0.16$ & \\
\hline & OciBest & $1.24 \pm 0.18$ & $0.77 \pm 0.14^{\mathrm{a}}$ & $0.51 \pm 0.11^{\mathrm{ab}}$ & $0.31 \pm 0.09^{\mathrm{ab}}$ & $0.93 \pm 0.15$ & 0.17 \\
\hline \multirow{2}{*}{ Palpitation at rest } & Placebo & $1.29 \pm 0.16$ & $0.76 \pm 0.12^{\mathrm{a}}$ & $0.66 \pm 0.11^{\mathrm{a}}$ & $0.51 \pm 0.11^{\mathrm{a}}$ & $0.78 \pm 0.15$ & \\
\hline & OciBest & $1.56 \pm 0.19$ & $0.93 \pm 0.14^{\mathrm{a}}$ & $0.59 \pm 0.12^{\mathrm{ab}}$ & $0.46 \pm 0.11^{\mathrm{ab}}$ & $1.10 \pm 0.17$ & 0.31 \\
\hline \multirow{2}{*}{ Abnormal perception of hearing } & Placebo & $0.25 \pm 0.09$ & $0.20 \pm 0.08$ & $0.18 \pm 0.06$ & $0.14 \pm 0.06$ & $0.11 \pm 0.05$ & \\
\hline & OciBest & $0.45 \pm 0.13$ & $0.30 \pm 0.09^{\mathrm{a}}$ & $0.27 \pm 0.09^{\mathrm{a}}$ & $0.21 \pm 0.08^{\mathrm{a}}$ & $0.24 \pm 0.08$ & 0.13 \\
\hline \multirow{2}{*}{ Blurring of vision } & Placebo & $0.51 \pm 0.13$ & $0.37 \pm 0.10$ & $0.28 \pm 0.08^{\mathrm{a}}$ & $0.29 \pm 0.09^{\mathrm{a}}$ & $0.22 \pm 0.07$ & \\
\hline & OciBest & $0.75 \pm 0.14$ & $0.45 \pm 0.10^{\mathrm{a}}$ & $0.31 \pm 0.09^{\mathrm{a}}$ & $0.28 \pm 0.09^{\mathrm{a}}$ & $0.46 \pm 0.11$ & 0.25 \\
\hline \multirow{2}{*}{ Forgetfulness } & Placebo & $1.25 \pm 0.17$ & $1.10 \pm 0.16$ & $0.99 \pm 0.15^{\mathrm{a}}$ & $0.95 \pm 0.15^{\mathrm{a}}$ & $0.30 \pm 0.08$ & \\
\hline & OciBest & $1.32 \pm 0.19$ & $1.03 \pm 0.16^{\mathrm{a}}$ & $0.87 \pm 0.14^{\mathrm{a}}$ & $0.32 \pm 0.08^{\mathrm{abc} *}$ & $1.00 \pm 0.15$ & 0.70 \\
\hline \multirow{2}{*}{ Sexual problems of recent origin } & Placebo & $0.71 \pm 0.16$ & $0.65 \pm 0.14$ & $0.61 \pm 0.14$ & $0.56 \pm 0.13$ & $0.15 \pm 0.05$ & \\
\hline & OciBest & $0.85 \pm 0.17$ & $0.75 \pm 0.16$ & $0.54 \pm 0.12^{\mathrm{a}}$ & $0.07 \pm 0.03^{\mathrm{abc}}{ }^{*}$ & $0.77 \pm 0.16$ & 0.62 \\
\hline \multirow{2}{*}{ Frequent GI symptoms } & Placebo & $1.61 \pm 0.18$ & $1.11 \pm 0.14^{\mathrm{a}}$ & $0.77 \pm 0.13^{\mathrm{ab}}$ & $0.59 \pm 0.11^{\mathrm{ab}}$ & $1.01 \pm 0.15$ & \\
\hline & OciBest & $1.63 \pm 0.20$ & $1.07 \pm 0.15^{\mathrm{a}}$ & $0.63 \pm 0.12^{\mathrm{ab}}$ & $0.44 \pm 0.10^{\mathrm{ab}}$ & $1.20 \pm 0.17$ & 0.18 \\
\hline \multirow{2}{*}{ Abnormal movements } & Placebo & $0.39 \pm 0.11$ & $0.35 \pm 0.11$ & $0.28 \pm 0.09$ & $0.20 \pm 0.08^{\mathrm{a}}$ & $0.19 \pm 0.08$ & \\
\hline & OciBest & $0.44 \pm 0.12$ & $0.27 \pm 0.10^{\mathrm{a}}$ & $0.23 \pm 0.09^{\mathrm{a}}$ & $0.20 \pm 0.08^{\mathrm{a}}$ & $0.24 \pm 0.08$ & 0.05 \\
\hline \multirow{2}{*}{ Abnormal sensory perceptions } & Placebo & $0.25 \pm 0.09$ & $0.16 \pm 0.06$ & $0.14 \pm 0.06$ & $0.15 \pm 0.07$ & $0.10 \pm 0.05$ & \\
\hline & OciBest & $0.48 \pm 0.13$ & $0.32 \pm 0.11^{\mathrm{a}}$ & $0.27 \pm 0.10^{\mathrm{a}}$ & $0.25 \pm 0.10^{\mathrm{a}}$ & $0.23 \pm 0.09$ & 0.12 \\
\hline \multirow{2}{*}{ Quarrelsome behavior } & Placebo & $1.06 \pm 0.17$ & $0.96 \pm 0.16$ & $0.82 \pm 0.15^{\mathrm{a}}$ & $0.65 \pm 0.12^{\mathrm{abc}}$ & $0.42 \pm 0.09$ & \\
\hline & OciBest & $0.90 \pm 0.19$ & $0.70 \pm 0.15^{\mathrm{a}}$ & $0.59 \pm 0.13^{\mathrm{a}}$ & $0.34 \pm 0.09^{\mathrm{abc}}$ & $0.56 \pm 0.13$ & 0.15 \\
\hline \multirow{2}{*}{ Frequent feeling of exhaustion } & Placebo & $2.00 \pm 0.17$ & $1.53 \pm 0.14^{\mathrm{a}}$ & $1.19 \pm 0.13^{\mathrm{ab}}$ & $1.04 \pm 0.14^{\mathrm{ab}}$ & $0.96 \pm 0.14$ & \\
\hline & OciBest & $1.72 \pm 0.19$ & $1.13 \pm 0.15^{\mathrm{a}}$ & $0.86 \pm 0.13^{\mathrm{a}}$ & $0.37 \pm 0.08^{a b c^{*}}$ & $1.35 \pm 0.17$ & 0.39 \\
\hline \multirow{2}{*}{ Frequent sleep problems } & Placebo & $1.49 \pm 0.17$ & $1.14 \pm 0.14^{\mathrm{a}}$ & $0.82 \pm 0.13^{\mathrm{ab}}$ & $0.84 \pm 0.14^{\mathrm{ab}}$ & $0.66 \pm 0.12$ & \\
\hline & OciBest & $1.30 \pm 0.19$ & $0.89 \pm 0.15^{\mathrm{a}}$ & $0.58 \pm 0.13^{\mathrm{ab}}$ & $0.27 \pm 0.08^{\mathrm{abc}^{*}}$ & $1.03 \pm 0.17$ & 0.37 \\
\hline \multirow{2}{*}{ Avoidance of even familiar people } & Placebo & $0.28 \pm 0.10$ & $0.23 \pm 0.08$ & $0.20 \pm 0.08$ & $0.20 \pm 0.08$ & $0.08 \pm 0.06$ & \\
\hline & OciBest & $0.38 \pm 0.12$ & $0.21 \pm 0.09^{\mathrm{a}}$ & $0.17 \pm 0.07^{\mathrm{a}}$ & $0.10 \pm 0.05^{\mathrm{a}}$ & $0.28 \pm 0.11$ & 0.21 \\
\hline \multirow{2}{*}{ Missing appointments } & Placebo & $0.14 \pm 0.07$ & $0.13 \pm 0.06$ & $0.05 \pm 0.03$ & $0.05 \pm 0.03$ & $0.09 \pm 0.05$ & \\
\hline & OciBest & $0.25 \pm 0.09$ & $0.14 \pm 0.07^{\mathrm{a}}$ & $0.11 \pm 0.06^{\mathrm{a}}$ & $0.07 \pm 0.04^{\mathrm{a}}$ & $0.18 \pm 0.07$ & 0.09 \\
\hline \multirow{2}{*}{ Total } & Placebo & $12.58 \pm 0.48$ & $9.66 \pm 0.44^{\mathrm{a}}$ & $7.77 \pm 0.46^{\mathrm{ab}}$ & $6.75 \pm 0.45^{\mathrm{abc}}$ & $5.84 \pm 0.54$ & \\
\hline & OciBest & $13.27 \pm 0.46$ & $8.96 \pm 0.43^{\mathrm{a}}$ & $6.52 \pm 0.45^{\mathrm{ab}}$ & $3.69 \pm 0.37^{a b c^{*}}$ & $9.58 \pm 0.52$ & 3.74 \\
\hline
\end{tabular}

Values are expressed as mean \pm SEM; Placebo $n=79$; OciBest $n=71$.

${ }^{\mathrm{a}} P \leq 0.05$ versus week 0 ; ${ }^{\mathrm{b}} P \leq 0.05$ versus week 2 ; ${ }^{\mathrm{c}} P \leq 0.05$ versus week 4 .

$* P \leq 0.05$ - placebo versus OciBest.

${ }^{\mathrm{X}}$ Difference in mean scores between week 0 and week $6 ;{ }^{\mathrm{Y}} \mathrm{D}$ ifference in mean scores between placebo and OciBest.

Sexual problems and stress are related in several ways. Psychological causes that arise due to work-related stress result in sexual problems. Excessive stress can lead to reduced libido/sex drive in both sexes $[34,35]$. Our findings showed that $O$. tenuiflorum extract remarkably reduced the symptom scores of sexual problems by $87.5 \%$ in comparison to patients of placebo group.

In contrast to acute stress that accelerates neurotransmitters and hormones from the nervous and endocrine systems which in turn will enhance immune system functions, chronic stress aggravates exhaustion, distress, and disease $[36,37]$. In the present investigation, OciBest administration provided effective relief from frequent feeling of fatigue. Similarly, disturbances in regular sleeping habits are encountered with stressful life style. Also, daytime sleepiness has been reported with prolonged stress exposures [38]. The results of the present clinical trial exhibited that the herbal intervention considerably reduced the intensity of symptom from $0.84 \pm 0.14$ to $0.27 \pm 0.08$.

The overall effects of extract of $O$. tenuiflorum in patients with stress were found to be significant as compared to placebo which can be attributed to the influence of herbal supplement on four major symptoms like forgetfulness, sexual problems of recent origin, frequent feeling of exhaustion, and frequent sleep problems. The probable mechanisms of adaptogenic effects, from previously established studies, could be ascribed to neuroprotective [39], immunostimulant [40], free radical scavenging [41], nonspecific resistance inducing and plasma cortisol lowering [42] effects of $O$. sanctum. 
Evidence-Based Complementary and Alternative Medicine

The major phytochemical principles of Holy Basil largely contribute to its pharmacological actions. Saravanan and Pugalendi in 2006 reported that the triterpenoid ursolic acid at $20 \mathrm{mg}$ per $\mathrm{kg}$ per day for 30 days could be able to ameliorate the oxidative stress in rat heart induced by chronic ethanol intoxication by reversing the peroxidative damages and concurrently enhancing the activities of antioxidant enzymes [43]. Another triterpenoid-Oleanolic acid protected mouse macrophages against oxidative and electrophile stress [39].

From the results of the present study, it is also evident that the severity of other symptoms such as headache, palpitation at rest, abnormal perception of hearing, blurring of vision, frequent GI symptoms, abnormal sensory perceptions, quarrelsome behavior, and avoidance of familiar people lessened to certain extent due to dietary supplementation. Although the scores of symptoms like abnormal movements of upper limb, tics, tremors, scratching, and missing appointments did not improve after six weeks of intervention, these symptoms are infrequently reported in stress patients. The positive trends of the present investigation can be corroborated with the research findings on O. tenuiflorum for stress management [44]. The different components of stress response include enhancement of central nervous system processes and the interaction between hypothalamuspituitary-adrenocortical (HPA) axis [45]. Bhattacharyya et al. stated that, in human subjects, O. sanctum acts potentially in the regulation of HPA axis in stress-related disorders [22].

On the other hand, analysis of study results also indicated presence of placebo effect to some extent which is commonly anticipated as a regular incidence in several clinical trials $[26,46]$. However, the critical observations on self-evaluated scores of study endpoints reinforce the fact that few symptoms in placebo group either remained constant (avoidance of even familiar people and missing appointments) or got aggravated (blurring of vision, abnormal sensory perceptions, and frequent sleep problems) from week 4 to week 6 .

Pertinent to safety, OciBest administration was found to be well tolerated in stress patients and no adverse events were recorded during the clinical trial. Earlier research by Bhattacharyya et al. in GAD patients also confirmed the overall safety of $O$. sanctum [22]. As mentioned previously, the wide margin of safety reported in experimental animal species tends to support the medicinal plant for human use [11].

In conclusion, the study findings revealed that OciBest, the whole plant extract of $O$. tenuiflorum, was found to be 1.6 times or $39 \%$ more effective in the management of stress symptoms in comparison to placebo group and the herbal supplementation was well tolerated by all the patients over the six weeks of study period.

\section{Acknowledgments}

The authors wish to thank Dr. Amit Agarwal and Dr. V. Vijayabalaji for providing technical support. R. Singh is a consultant at General Medicine and Cardiology, Lucknow.

\section{References}

[1] S. Palmer, "Occupational Stress," The Health and Safety Practitioner, vol. 7, pp. 16-18, 1989.

[2] I. M. Bakker, B. Terluin, H. W. J. Van Marwijk et al., "Effectiveness of a Minimal Intervention for Stress-related mental disorders with Sick leave (MISS); study protocol of a cluster randomised controlled trial in general practice [ISRCTN43779641]," BMC Public Health, vol. 6, article no. 124, 2006.

[3] C. Burton, "Beyond somatisation: a review of the understanding and treatment of medically unexplained physical symptoms (MUPS)," British Journal of General Practice, vol. 53, no. 488, pp. 231-239, 2003.

[4] OECD Economic Surveys: Netherlands: Reform of the sickness and disability benefit schemes, 2004.

[5] D. Anderson, "Assessment and nutraceutical management of stress-induced adrenal dysfunction," Integrative Medicine, vol. 7, pp. 18-28, 2008.

[6] Anonymous, America's No.1 health problem: why is there more stress today? The American Institute for Stress, 2011, http://www.stress.org/ americas.htm.

[7] Anonymous, Just how serious is the problem? Facts and figures about stress in the workplace, Human Nature at Work, 2011, http://www.humannatureatwork.com/serious.htm.

[8] A. Kimanen, P. Manninen, K. Räsänen, M. Rautio, P. Husman, and K. Husman, "Factors associated with visits to occupational health physicians in Finland," Occupational Medicine, vol. 60, no. 1, Article ID kqp128, pp. 29-35, 2009.

[9] J. J. L. Van der Klink, R. W. B. Blonk, A. H. Schene, and F. J. H. Van Dijk, "The benefits of interventions for work-related stress," American Journal of Public Health, vol. 91, no. 2, pp. 270-276, 2001.

[10] V. Gupta, A. Gupta, S. Saggu et al., "Anti-stress and adaptogenic activity of L-Arginine supplementation," Evidence-Based Complementary and Alternative Medicine, vol. 2, pp. 93-97, 2005.

[11] S. B. Kasture, V. S. Kasture, A. J. Joshua, A. Damodaran, and A. Amit, "Nootropic activity of BacoMind, an enriched phytochemical composition from Bacopa monnieri," Journal of Natural Remedies, vol. 7, no. 1, pp. 166-173, 2007.

[12] U. P. Dave, P. Wasim, J. A. Joshua et al., "A cognitive enhancer in children requiring individual education programme," Journal of Pharmacology and Toxicology, vol. 3, pp. 302-310, 2008.

[13] H. C. Barbhaiya, R. P. Desai, V. S. Saxena et al., "Efficacy and tolerability of BacoMind ${ }^{\circledR}$ on memory improvement in elderly participants - a double blind placebo controlled study," Pharmacology and Toxicology, vol. 3, pp. 425-434, 2008.

[14] K. P. Bhargava and N. Singh, "Anti-stress activity of Ocimum sanctum Linn," Indian Journal of Medical Research, vol. 73, pp. 443-451, 1981.

[15] S. Godhwani, J. L. Gowdhwani, and D. S. Vyas, "Ocimum sanctum: an experimental study evaluating its anti-inflammatory, analgesic and antipyretic activity in animals," Journal of Ethnopharmacology, vol. 21, pp. 153-163, 1987.

[16] S. Singh and S. S. Agrawal, "Anti-asthmatic and anti-inflammatory activity of Ocimum sanctum," Pharmaceutical Biology, vol. 29, pp. 306-310, 1991.

[17] M. A. Kelm, M. G. Nair, G. M. Strasburg, and D. L. DeWitt, "Antioxidant and cyclooxygenase inhibitory phenolic compounds from Ocimum sanctum Linn," Phytomedicine, vol. 7, no. 1, pp. 7-13, 2000. 
[18] S.K. Bhattacharya, A. Bhattacharya, K. Das, A. V. Muruganandam, and K. Sairam, "Further investigations on the antioxidant activity of Ocimum sanctum using different paradigms of oxidative stress in rats," Journal of Natural Remedies, vol. 1, pp. 6-16, 2001.

[19] N. Khanna and J. Bhatia, "Antinociceptive action of Ocimum sanctum (Tulsi) in mice: possible mechanisms involved," Journal of Ethnopharmacology, vol. 88, no. 2-3, pp. 293-296, 2003.

[20] S. Singh, V. Nair, S. Jain, and Y. K. Gupta, "Evaluation of antiinflammatory activity of plant lipids containing $\alpha$-linolenic acid," Indian Journal of Experimental Biology, vol. 46, no. 6, pp. 453-456, 2008.

[21] N. Singh, N. Misra, A. K. Srivastava, K. S. Dixit, and G. P. Gupta, "Effect of anti-stress plants on biochemical changes during stress reaction," Indian Journal of Pharmacology, vol. 23, pp. 137-142, 1991.

[22] D. Bhattacharyya, T. K. Sur, U. Jana, and P. K. Debnath, "Controlled programmed trial of Ocimum sanctum leaf on generalized anxiety disorders," Nepal Medical College Journal, vol. 10, no. 3, pp. 176-179, 2008.

[23] M. S. Lee, M. S. Park, Y. I. Shin, B. S. Moon, and W. H. Woo, "Effects of a Korean traditional herbal supplement on symptoms of stress and mood profiles in high school girls: a randomized, double blind, placebo-controlled trial," Stress and Health, vol. 21, no. 2, pp. 139-143, 2005.

[24] R. B. Dell, S. Holleran, and R. Ramakrishnan, "Sample size determination," ILAR Journal, vol. 43, no. 4, pp. 207-213, 2002.

[25] I. M. Bakker, B. Terluin, H. W. J. van Marwijk et al., "A clusterrandomised trial evaluating an intervention for patients with stress-related mental disorders and sick leave in primary care," PLoS Clinical Trials, vol. 2, no. 6, article no. e26, 2007.

[26] V. Darbinyan, A. Kteyan, A. Panossian, E. Gabrielian, G. Wikman, and H. Wagner, "Rhodiola rosea in stress induced fatigue - a double blind cross-over study of a standardized extract SHR-5 with a repeated low-dose regimen on the mental performance of healthy physicians during night duty," Phytomedicine, vol. 7, no. 5, pp. 365-371, 2000.

[27] D. S. Kalman, S. Feldman, R. Feldman, H. I. Schwartz, D. R. Krieger, and R. Garrison, "Effect of a proprietary Magnolia and Phellodendron extract on stress levels in healthy women: a pilot, double-blind, placebo-controlled clinical trial," Nutrition Journal, vol. 7, no. 1, article no. 11, 2008.

[28] M. A. Milesi, D. Lacan, H. Brosse, D. Desor, and C. Notin, "Effect of an oral supplementation with a proprietary melon juice concentrate (Extramel) on stress and fatigue in healthy people: a pilot, double-blind, placebo-controlled clinical trial," Nutrition Journal, vol. 8, no. 1, article no. 40, 2009.

[29] C. V. Chandrasekaran, P. Thiyagarajan, K. Sundarajan et al., "Evaluation of the genotoxic potential and acute oral toxicity of standardized extract of Andrographis paniculata (KalmCold)," Food and Chemical Toxicology, vol. 47, no. 8, pp. 1892-1902, 2009.

[30] A. J. Joshua, K. S. Goudar, A. Damodaran, N. Sameera, and A. Amit, "Acute oral toxicity evaluation of some polyherbal formulations in albino wistar rats," International Journal of Pharmacology, vol. 4, no. 5, pp. 388-392, 2008.

[31] K. Pravina, K. R. Ravindra, K. S. Goudar et al., "Safety evaluation of BacoMind in healthy volunteers: a phase I study," Phytomedicine, vol. 14, no. 5, pp. 301-308, 2007.

[32] A. Amit, V. S. Saxena, N. Pratibha, M. Bagchi, D. Bagchi, and S. J. Stohs, "Safety of a novel botanical extract formula for ameliorating allergic rhinitis," Toxicology Mechanisms and Methods, vol. 13, no. 4, pp. 253-261, 2003.

[33] S. Jain, Improve Your Memory: The Neuroscience, Prabhat Prakashan, 2009.

[34] G. Bodenmann, T. Ledermann, D. Blattner, and C. Galluzzo, "Associations among everyday stress, critical life events, and sexual problems," Journal of Nervous and Mental Disease, vol. 194, no. 7, pp. 494-501, 2006.

[35] G. Bodenmann, T. Ledermann, and T. N. Bradbury, "Stress, sex, and satisfaction in marriage," Personal Relationships, vol. 14, no. 4, pp. 551-569, 2007.

[36] X. Y. Zhang, D. F. Zhou, L. Y. Cao, G. Y. Wu, and Y. C. Shen, "Cortisol and cytokines in chronic and treatment-resistant patients with schizophrenia: association with psychopathology and response to antipsychotics," Neuropsychopharmacology, vol. 30, no. 8, pp. 1532-1538, 2005.

[37] T. Esch, G. B. Stefano, G. L. Fricchione, and H. Benson, "The role of stress in neurodegenerative diseases and mental disorders," Neuroendocrinology Letters, vol. 23, pp. 199-208, 2002.

[38] N. Salahuddin, J. Barroso, J. Leserman, J. L. Harmon, and B. W. Pence, "Daytime Sleepiness, Nighttime Sleep Quality, Stressful Life Events, and HIV-Related Fatigue," Journal of the Association of Nurses in AIDS Care, vol. 20, no. 1, pp. 6-13, 2009.

[39] A. T. Dinkova-Kostova, K. T. Liby, K. K. Stephenson et al., "Extremely potent triterpenoid inducers of the phase 2 response: correlations of protection against oxidant and inflammatory stress," Proceedings of the National Academy of Sciences of the United States of America, vol. 102, no. 12, pp. 4584-4589, 2005.

[40] S. Godhwani, J. L. Godhwani, and D. S. Vyas, "Ocimum sanctum-a preliminary study evaluating its immunoregulatory profile in albino rats," Journal of Ethnopharmacology, vol. 24, no. 2-3, pp. 193-198, 1988.

[41] S. Balanehru and B. Nagarajan, "Intervention of Adriamycin induced free radical damage," Biochemistry International, vol. 28, no. 4, pp. 735-744, 1992.

[42] K. Sembulingam, P. Sembulingam, and A. Namasivayam, "Effect of Ocimum sanctum Linn on noise induced changes in plasma corticosterone level," Indian Journal of Physiology and Pharmacology, vol. 41, pp. 139-143, 1997.

[43] R. Saravanan and V. Pugalendi, "Impact of ursolic acid on chronic ethanol-induced oxidative stress in the rat heart," Pharmacological Reports, vol. 58, no. 1, pp. 41-47, 2006.

[44] P. Sen, P. C. Maiti, S. Puri, A. Ray, N. A. Audulov, and A. V. Valdman, "Mechanism of anti-stress activity of Ocimum sanctum Linn, eugenol and Tinospora malabarica in experimental animals," Indian Journal of Experimental Biology, vol. 30, no. 7, pp. 592-596, 1992.

[45] J. J. Haddad, N. E. Saade, and B. Safieh-Garabedian, "Cytokines and neuro-immune-endocrine interactions: a role for the hypothalamic-pituitary-adrenal revolving axis," Journal of Neuroimmunology, vol. 133, pp. 1-19, 2002.

[46] C. C. McCann, B. Goldfarb, M. Frisk, M. A. Quera-Salva, and P. Meyer, "The role of personality factors and suggestion in placebo effect during mental stress test," British Journal of Clinical Pharmacology, vol. 33, no. 1, pp. 107-110, 1992. 


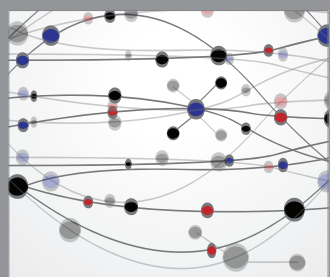

The Scientific World Journal
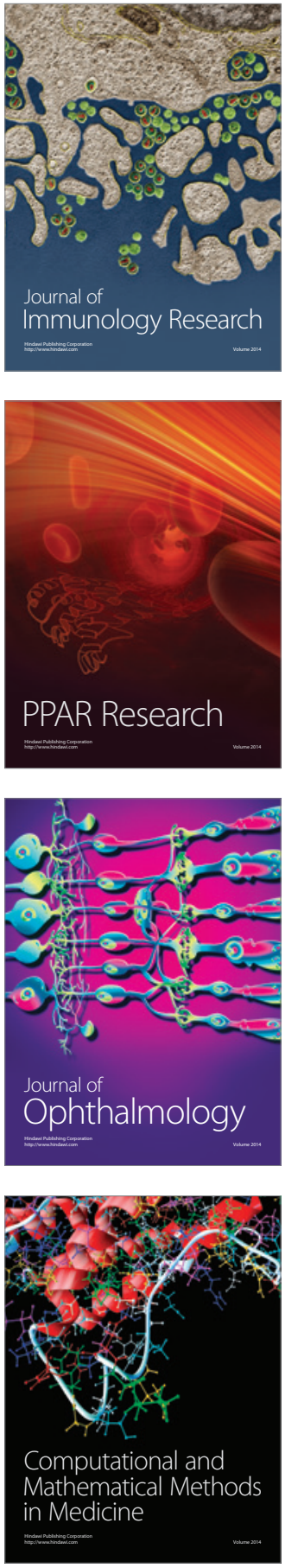

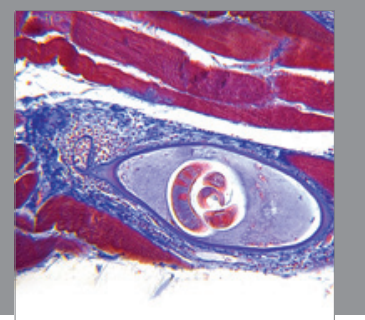

Gastroenterology

Research and Practice
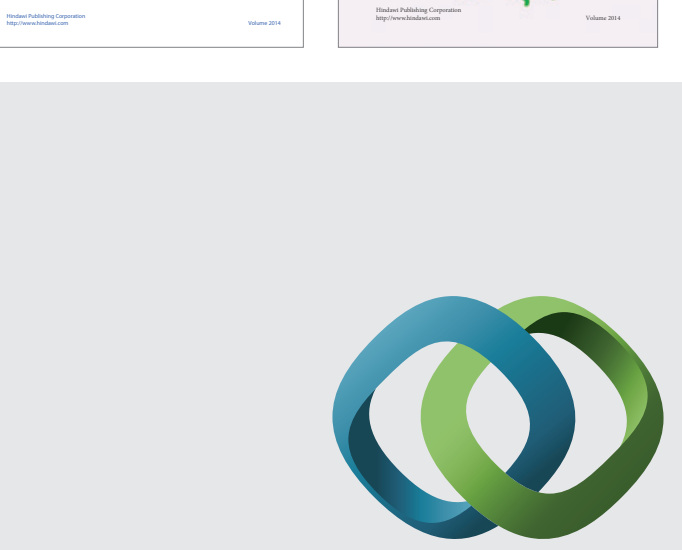

\section{Hindawi}

Submit your manuscripts at

http://www.hindawi.com
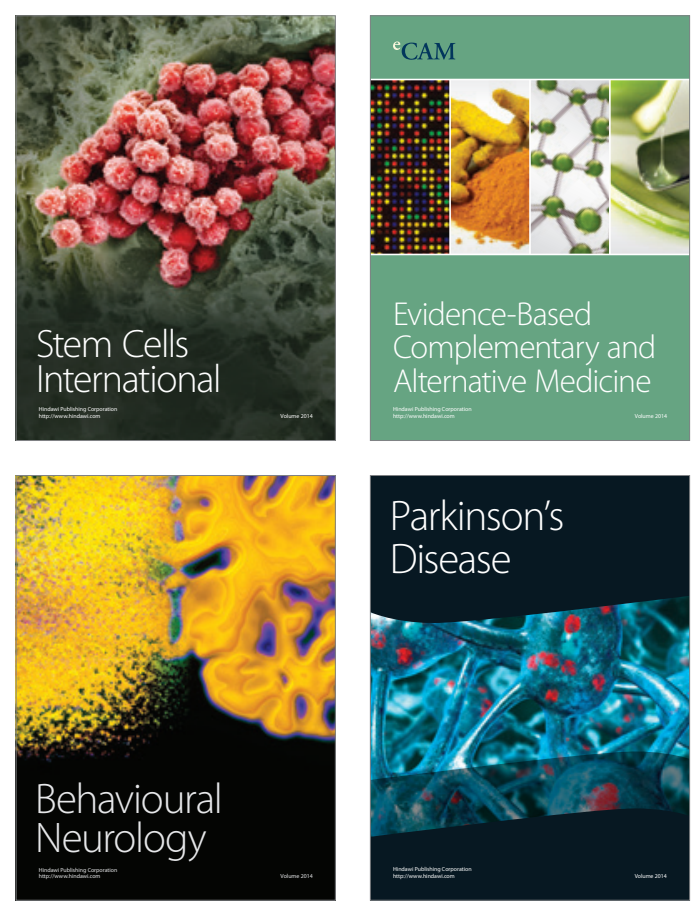

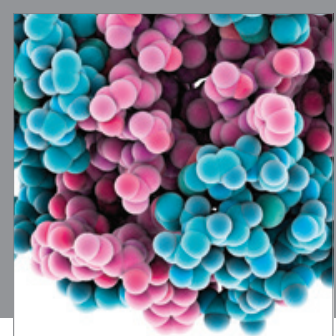

Journal of
Diabetes Research

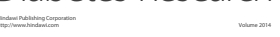

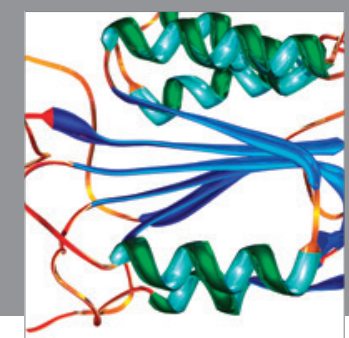

Disease Markers
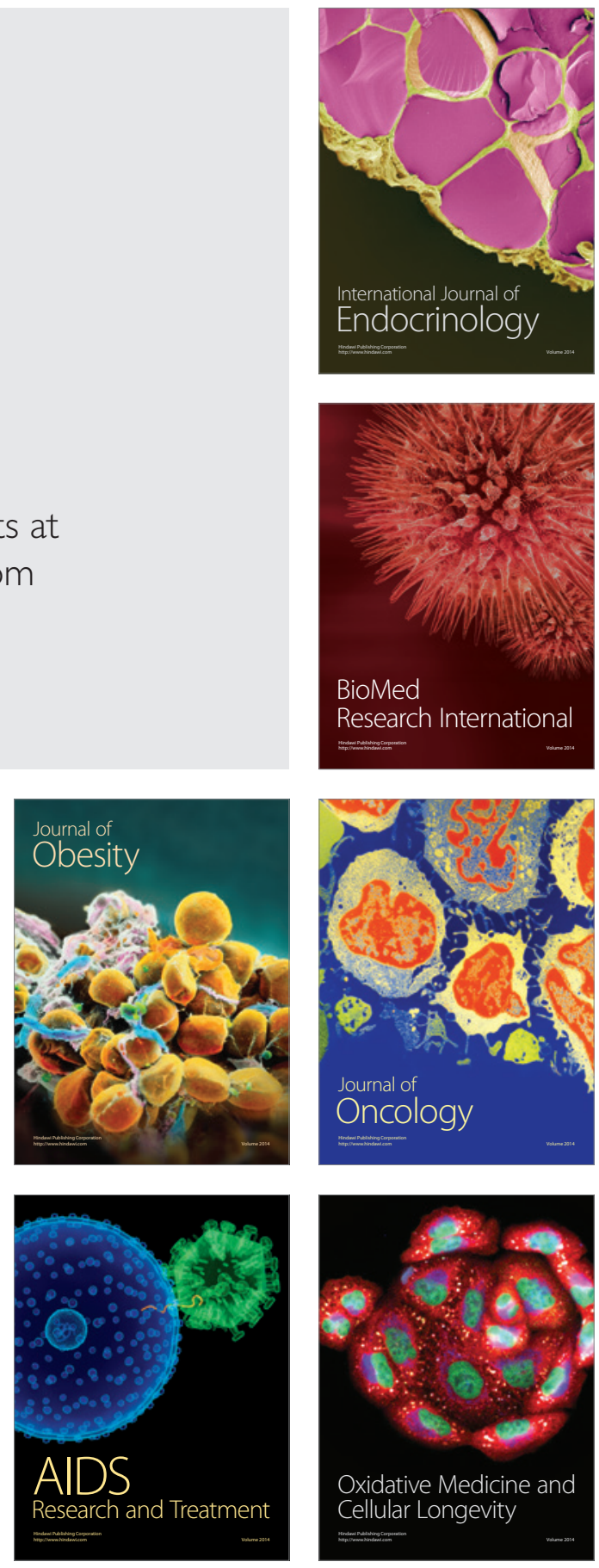